\title{
Visual Inspection based Maintenance Strategy on Unsealed Road Network in Australia
}

\author{
Vasantsingh Pardeshi ${ }^{1}$, and Sanjay Nimbalkar ${ }^{2 \#}, \mathrm{PhD}$ \\ ${ }^{1}$ Postgraduate Student, School of Civil \& Environmental Engineering, University of Technology Sydney NSW 2007 \\ Australia, Email: VasantsinghBhimsingh.Pardeshi@student.uts.edu.au \\ ${ }^{2}$ Lecturer, School of Civil \& Environmental Engineering, University of Technology Sydney NSW 2007 Australia, \\ Email: Sanjay.Nimbalkar@uts.edu.au (corresponding author ${ }^{\#}$ )
}

\begin{abstract}
Gravel loss on unsealed roads is financially a major setback for all road agencies. The maintenance strategy in Australia is primarily based on visual inspection only which has inherent drawbacks. It is also environmentally unsustainable. Key challenges associated with the unsealed road management are identified as (i) difficulty to forecast behaviour, (ii) significant data collection needs and (iii) vulnerability in level of service \& maintenance practices. The quality of gravel material is one of the major influencing factors. Various theoretical models have developed in the past to estimate gravel loss. These studies are used to estimate road deterioration and maintenance strategy in practice. A range of approaches such as regression analysis of field measured data, system dynamic modelling approach, laboratory measurements have been employed in the past. In the state of Queensland of Australia, the long-term gravel loss monitoring is planned in the region affected by frequent flood to assess the amount of gravel loss and associated maintenance issues. Recently, a mammoth maintenance work was undertaken on unsealed road network to cater for gravel loss due to Ex Tropical Cyclone Debbie. Visual inspection can be a useful tool to provide snapshot of unseal road network at a time. Most road agencies still use this visual inspection as a maintenance strategy tool. It is recommended in this study to integrate visual inspection with localised gravel loss model and roughness data. GPS based data can be integrated by using visual inspections, roughness and the gravel model.
\end{abstract}

Keywords: gravel loss, unsealed road, visual inspection, theoretical model

\section{INTRODUCTION}

Australia has a staggering 574,660 km of gravel roads, comprising more than $60 \%$ of the nation's road length. Most of these unsealed roads are the responsibility of their local council, which is onerous task considering many rural and regional councils cover huge areas and have only a small population to try to meet the costs to maintain this network. Queensland State has $51,482 \mathrm{~km}$ of unsealed road length. It compromises 38\% sealed road network and 62\% unsealed road network. Scenic Rim Regional Council (SRRC) is responsible to maintain a huge network of sealed and unsealed roads. SRRC has a road network of $1,816 \mathrm{kms}$, which compromises of $955 \mathrm{kms}$ of sealed roads, $861 \mathrm{kms}$ of unsealed roads and a small number of unpaved roads. SRRC has $47.42 \%$ unsealed road network and $52.58 \%$ of unsealed road network.

For about 500,000 km length of unsealed roads in Australia approximate maintenance cost per year is A 1 Billion dollars. SRRC annual maintenance budget on unsealed road is about a 2 Million dollars per year. Gravel roads are the economic backbone of Australia that depend on mining, farming and forestry. Those low traffic volume roads cannot be upgraded to sealed roads. As stated in first paragraph Australia's unsealed road network is around $60 \%$ of the whole road network and requires about $20 \%$ to $30 \%$ of the total road maintenance cost. It is large part of the road infrastructure cost. Societies in rural and regional Australia depend on the unsealed road network for transportation of produce and people on this road network. Major complaints across many councils pertaining to gravel 
roads are related to dust, potholes and either slippery road after wet weather or loose stones after long period of dry weather.

This paper provides background information relevant to unsealed roads, problems/concerns related to unsealed roads and maintenance. Emphasis is on visual inspections for maintenance management and priorities. Advantages and limitations of visual inspections and how visual inspection can be used in a better way using GPS applications to provide visual data. This paper provides a case study on unsealed road network within SRRC. SRRC unsealed road maintenance strategy is developed with visual inspection only. It also provides brief overview on how a unseal road research project was initiated due to Ex tropical Cyclone Debbie.

\section{Challenges Associated with Maintenance and Management of Unsealed Roads}

Unsealed roads considered in this research are low volume road (generally 20 to 500 vehicles per day) designed to the appropriate design standards with necessary drainage. This unsealed road has a layer of granular material which is compacted. The thickness of this compacted layer is dependent on traffic loading. It is required to maintain unsealed road regularly. It is worth mentioning that sealed roads are the ones with top layer either spray seal or asphalt which protects the underneath pavement layers from water ingress.

Dust emission and uncomfortable driving conditions are two main complaints encountered by local road authorities. Many research projects have struggled to forecast unsealed road problems. A common challenge for most of the predicting models is the intricate relationship between gravel quality (properties), maintenance practices, weather, drainage, construction practices and, geometric design. There are two tactics used for unsealed road data collection. First is to gather a substantial number of condition data regularly. Second one is road inspections by professionals to evaluate the complete condition of the unsealed network. The first tactic causes a substantial burden on road agencies, while second tactic lacks information for strategic planning. Due to neither approach is entirely reasonable, data collection methods with most road agencies varies significantly according to ad-hoc practices. Due to the flexible acceptance of specifications for unsealed roads over sealed roads, there is a large discrepancy for the levels of service on unsealed roads and the maintenance practices. There are huge variances in the geology, landscape, subgrades, environment and material between areas, which causes large variances in unsealed road performance. A reliable planning method that delivers for these variances is not possible.

'The Unsealed Roads Manual, Guidelines to Good Practice, 3rd edition March 2009' covers management procedures and practices for unsealed road network in Australian and New Zealand. This manual was developed by George Giummarra from Australian Road Research Board (ARRB). ARRB has clearly indicated that unsealed roads are presently managed with very little technical input. Due to this lack of technical input, full benefit is not realised from the available funding. The Unsealed Roads Manual provides a sound technical base for various areas relating to design, construction and maintenance of unsealed roads. Local and State Government authorities and other agencies are the major beneficiary of this manual. Unsealed Roads Tactical Asset Management Manual (August 2015) in New Zealand also mentions significant dependence on exhaustive data collection. The issues with gathering data related to unsealed road management systems are:

- $\quad$ Specific material characteristics normally do not exist for individual unsealed roads

- Unseal road condition can change significantly in short period of time, which makes existing data not relevant after it has collected

- Regular data collection is needed to for the management system adequately reliable. But regular data collection sometimes is not be cost effective and can be demanding task for road agency. 


\section{UNSEALED ROAD MAINTENANCE TYPES}

The maintenance for unsealed roads can be categorised into two major types: periodic maintenance which is performed on yearly basis programme and monthly or predetermined frequency ( 2 to 6 months) routine maintenance based on cyclic programme. Periodic maintenance is long term regravelling which requires to address gravelling timing, quantity of gravel which is gravel layer thickness. Routine maintenance of unsealed road targets surface defects only for which route cause is traffic and weather conditions. Routine maintenance programme revolves around grading programme. Grading programme is governed by level of service depending on availability of maintenance funds and managing road user expectations.

In Australia different types of grading are light, medium, heavy and resheeting. A Light formation grading is to restore rideability. Where the road is formed, and loss of shape and material is minor only, a Light formation grading may be appropriate to restore shape. Medium formation grading is to restore the road surface to profile and condition. Work includes roughening of top 50mm of roadway (by grader), clearing and grubbing to remove light vegetation and grass, recovery of suitable material from table drains (by grader), incorporation of water and compaction. No material is imported for this activity. Heavy Formation grading is to rreinstatement of formation and profile of road. Work include clearing and grubbing and recovery of suitable material from table drains (by grader), tyne less than $100 \mathrm{~mm}$ depth, incorporation of additional gravel/material, trimming, and compaction. Resheeting is the addition of imported gravel/material to the roadway to reinstate the running surface and correct profile. Work include preparation of the formation through heavy formation grading. Supply and spreading of imported gravel/material. Imported material should be consistent with the existing gravel material.

In New Zealand grading is also divided into different types: routine grading, cut out grading, dry weather grading, wet weather grading and so on. Routine grading is to maintain the road in smooth rideable condition and removing potholes and corrugations by not changing the pavement cross section. Cut out grading is cuts in the table drain or high shoulders to drain out surface runoff from pavement. Dry weather grading is mainly during drought conditions to manage loose pavement material top of pavement surface. This loose material is deposited on the side so that it can be respread when water becomes available at later date. Wet weather grading is when the pavement has better moisture content. Ideal timing is after rain when there is optimum moisture in the pavement. Grading Cycle also depends on traffic volumes, road and weather conditions i.e. rainfall, winter, summer drought conditions, harmonization with renewal of road works e.g. the gravelling and resheeting programmes, public complaints and political pressures and level of service the client requires.

\section{UNSEALED ROAD INSPECTION TYPES}

Unsealed road inspections can be classified into two major types Periodic condition surveys and routine inspections. Periodic condition surveys are GPR, Roughnesss, visual, drainage inspections. Routine inspections are monthly inspections by maintenance crew, client audits and inspections based on public complaints.

\section{Periodic Condition Surveys}

Ground Penetrating Radar (GPR) surveys can be used to record gravel thickness and other relevant data on Unsealed roads. The measuring antenna and the software used to analyse for GPR have been improved during last decade. There is a misunderstanding that GPR can provide precise gravel layer thicknesses. The GPR data analysis is time consuming and requires expert interpretation and costly. Roughometer type surveys use roughness meters and cell phone applications such as Road Roid for unsealed road data surveys. During recent years the roughometer devices which can measure roughness on an unsealed road have developed by leaps and bounds. The location is recorded using 
GPS (Global Positioning System) receiver and a roughness value is also recorded by a sensor attached to vehicle suspension. The results are mapped graphically due to GPS data which can be compared with previous surveys. Frequent roughness surveys are useful to compare similar problem identified. A better drainage which keeps away water from pavement plays major role in maintaining the road in good condition. Drainage Inspections are carried out by asset management team or field staff.

\section{Routine Inspections}

Field foreman perform visual inspections at predetermined frequency from monthly to quarterly of an unsealed network. This monthly inspection is for maintenance crew which carries out small repairs like potholes and associated fillings. Maintenance graders locations and activities are recorded using a netbook or tablet fitted in the grader in New Zealand. These records can be viewed on screen or exported to a GIS system for further comparison. Routine Grading can be classified one more type of inspections. The routine grader operator who has been on the network or part of network for a long period of time and has developed a better understanding of the unsealed network can be very useful to the maintenance team while carrying out grading work. This grader operator may help routine crews repairing and other maintenance activities. Most Road authorities or local councils have a customer request management (CRM) system to record and tress calls of consumers or road users. These CRM are used by road authorities to maintenance crew to inspect, analyse and determine needs for maintenance activities. Analysis of those CRM's can help for planning of routine and maintenance of unsealed road network.

\section{CASE STUDY: UNSEALED ROAD MAINTENANCE AND VISUAL CONDITION ASSESSMENT AT SRRC}

SRRC area is 4,200 square kilometres and 40,000 people call it a home. The region is surrounded by mountain ranges on east, south and west. On $30^{\text {th }}$ and $31^{\text {st }}$ March 2017 the rainfall produced by Cyclone Debbie and the cold front meeting over the SRRC ranged from 350mm in the West of the Scenic Rim region to $800 \mathrm{~mm}$ in the East of the Scenic Rim region in a 24-hr period. The annual average rainfall for Scenic Rim was $892 \mathrm{~mm}$ (Cryna weather station). The 24-hr flood event was approximately equal to the annual rainfall. This high rainfall in short periods of time created ground water velocities causing sever scour damage to most gravel surfaces. Sealed roads suffered very little damage, while gravel roads and bridges received major damage. Figure 1 shows the SRRC area.

Due to large amount of gravel road involved and many roads now getting reconstructed (regravelling and resheeting) SRRC has initiated gravel road research project. Aim of this project is to enhance the existing gravel material specification, measure gravel loss on this new modified gravel material, calibrate the existing gravel loss models, refine those existing gravel loss models to better suit SRRC area. Based on those refined models the gravel road maintenance strategy will be developed.

The maintenance strategy and visual inspection is discussed briefly here. The current Maintenance Management Manual (MMM) provides guidance for programming and prioritisation of defects for sealed and unsealed roads. MMM provides maintenance management system with regular inspection of road network and it is anticipated that road defects will be identified and programmed for inspection. A comprehensive intervention level response time per activity listing is provided in an annexure to this manual. Where intervention levels are exceeded, these must be highlighted at Works meetings. The Works Manager is to review the list of all activities with exceeded intervention levels and reprioritise, assign more resource or employ external contractors. It is common that low risk activities are often pushed back in favour of new high-risk activities. A suggested process for this is to increase the priority level every time an activity intervention level is exceeded. In this way the activity will become high enough to receive attention.

Council engages external contractors to undertake condition assessments of sealed roads, unsealed roads and footpath. Condition assessments of unsealed roads and footpath is carried out each year. 
The data produced from these assessments is fundamental to assess, programme and manage road assets. Table 1 provides details of the inspection frequency based on road category. Road Category is dependent on annual traffic per day. Unsealed roads within SRRC are under category from 5a to $5 \mathrm{~d}$. Higher volume roads are inspected more frequently and lower volume roads are less frequently.

In addition, Council undertakes inspections on all road infrastructure on a timely manner according to the Council's road hierarchy. The higher-class roads are given higher priority in inspection whereas lower class roads receive lower priority. Defects are identified by Road Name, Chainage, Type of defect e.g. pavement failure, gravel resheeting, shoulder resheeting etc and Maintenance Area. Condition rating is completed using an electronic platform called 'Reflect' which is asset management database software. This system uses the data entered to analyse the roads and provide a condition rating B. Safety Inspections are carried out on all roads listed on Council's Road Asset Register during the month of August on an annual basis. An additional annual Safety inspection are carried out on Roads with an estimated AADT in excess of 400 vpd during the month of February. Condition inspections are carried out annually during the months of October, November and December. This timeframe allows the information gathered to be collated and assessed for possible budget submissions. Condition Inspections may be required at irregular intervals due to unforeseen circumstances such as higher than average rainfall. In cases such as this, only the effected locations would be inspected to determine network needs.

\section{Visual Condition Assessment}

AT SRRC Visual Condition Assessment of unsealed road network is carried out by capturing video imagery and then the assessment of road segments with assessment criteria. This video imagery is recorded by asset management company. Integrated Road Survey Vehicle (IRSV) is used to capture video imagery of a road network. This imagery is recorded at every $100 \mathrm{~m}$ of road section intervals and in the direction of IRSV travel. The data is also provided with an accurate GIS layer representing the location of each $100 \mathrm{~m}$ assessment. This data is linked to a GIS road segment.

The condition assessment definitions are scored from 1 to 5, based on surface condition. Condition 9 is used to indicate an unmaintained or non-existent pavement structure which is commonly known as track. Surface condition major categories are loss of material, roughness, scouring and potholes, corrugations and shape. Based on surface condition and the score from 1 to 5, a condition rating guidance matrix is developed. Table 2 provides details of the condition rating criteria used by SRRC and external contractor to record data during visual inspection.

Condition 1, indicates a pavement in a sound state of service. Condition 2, indicates pavement in reasonable state of service. Condition 3, indicates pavement in a fair state of service. Condition 4, indicates a pavement in poor service condition. Condition 5 , indicates a pavement in extremely poor service condition. These conditions rating are generic and do not consider the type of gravel. These condition definitions are widely used by many local authorities in Australia. The total extent of the specific defects or condition score for every $100 \mathrm{~m}$ assessment section, is calculated and reported either total extents or average conditions score to one decimal place accuracy. It is also linked to GIS road segment.

Figure 2 represents the visual average score for the entire unsealed road network. One set is for 2017 and 2 sets for 2018. There was deliberate decision to condition assess twice in a year due to rapidly changing gravel network and funding approvals. This visual data was quite useful for flood repair approvals from the funding agencies. February 2017 assessment was a month prior to Cyclone Debbie and the other two assessments are post Cyclone Debbie and flood recovery work. There are noticeable changes in network condition. During 2017 there was only $10 \mathrm{~km}$ of network under condition 1 and majority was under condition 2 and $3(725 \mathrm{~km})$. After cyclone as the flood repair work is progressing there is noticeable increase of condition $1(95 \mathrm{~km})$. Condition 2 and 3 together are $614 \mathrm{~km}$. Since 2017 
to 2018 length of road under condition 1 and 2 has increased whereas length of road under condition 3 has decreased. This is because of resheeting and regravelling work completed during 2018.

Figure 3 is a graphical representation of maintenance strategy based on visual condition assessment. It displays total length of road under 3 major categories: No maintenance required (combined condition rated sections of 1 and 2), Requires maintenance (condition rated sections of 3), Priority maintenance (combined condition rated sections of 4 and 5).

Figure 4 shows the SRRC unsealed road condition map with colour coded condition rated roads. As this map is produced after the $70 \%$ completion of flood recovery works the whole network is in better condition. The network assessed in condition states requiring intervention usually reviewed with the high definition video imagery through the GIS or AMS by local works coordinators or managers who then prioritise and distribute maintenance resources having regard for their own judgement and experience and considering the operational circumstances at that time.

Visual Assessment has been a good tool on a network basis but it is based on surface condition and does not include gravel type. From Pavement and structural stability point of view there is need for better technique or assessment.

\section{GRAVEL LOSS MONITORING, ASSESSMENT AND EXPECTED OUTCOMES}

SRRC has started resheeting and regravelling unsealed road network damaged during Ex Tropical Cyclone Debbie. SRRC has initiated gravel loss and maintenance strategy development project for unsealed road network. Under this project 56 gravel loss monitoring stations are established. There are 23 stations in the east region and 33 stations in the west region.

To reduce the resource demand and improve efficiency in data collection latest GIS App and QGIS software is used. Gravel loss monitoring will continue for 2 years and the Martin 2013 (ARRB) gravel loss model will be further refined for localised conditions. While completing the resheeting and regravelling the gravel material specification is amended and improved. The gravel material is sourced using this updated specification. Aim is to reduce gravel loss by use of this improved material. The material specification will be further developed during this study for wet and dry weather conditions. In addition to gravel loss measurement using gravel loss stations SSRC is measuring roughness on the section of roads where gravel monitoring stations are established. The aim of this roughness measurement is to establish any relationship between gravel loss and roughness on the road. The gravel loss at particular station provides cross section of the road over period of time. Roughness provides the roughness level along the road to driving condition.

\section{ADVANTAGES AND LIMITATIONS OF VISUAL INSPECTIONS}

Visual inspections provide snapshot of network. It is very good tool for Asset manager to demonstrate the overall condition of unsealed road network in a particular time frame. It provides condition rating of a particular road or a section of road. Visual inspections can be summarised to provide stakeholders

and customers at what condition network is. For stakeholder or customer complaints it is possible to check for quick review as a desktop if not in a position to go and visit site. Ease to assess improvement or degradation of overall network based on summary report. Provided the inspection is carried out annually it is possible to work out if network is improving or degrading and what rate. It is good insurance policy in case of flood, safety incidents/ accidents. Even though the visual condition assessment is focused on surface characteristics and functionality of asset it is possible to use video imagery to check for safety incidents/accidents related to customer claims or investigations. Although author does not support this idea but at some instances it may be useful as a historical record.

Being visual inspection there is inherent limitation not able to provide overall condition (Subgrdae, 
drainage). Difficulty to develop routine maintenance program based on visual condition rating as this inspection identifies only surface defects gravel depths are not measured and similarly drainage problems. Due to rapidly changing characteristic of unsealed roads makes it difficult to justify usefulness of visual inspections

Data collection and management of unsealed roads are focused on operational processes and lack of useful information at tactical and strategic level (Henning et .al. 2019). 'Assessment Process for the Condition of Unsealed Roads, NZ Transport Agency research report' recommends further development performance reporting and system to assist with analysis for tactical levels. SRRC visual inspections provides higher level of maintenance strategy based on road lengths requiring immediate attention. Those areas can be further investigated in detail using other decision-making frameworks which can add value to the unsealed road management process.

\section{CONCLUSION}

It is difficult to predict unsealed road behaviour hence decision frameworks for unsealed roads are normally a combination of practical and theoretical approaches. Managing unsealed roads often involves operational issues, because unsealed roads change very quickly and when defects appear they must be addressed within a short response time. Many times, routine and cyclic maintenance is planned and scheduled according to routine inspections and experience from road operators.

However, longer-term maintenance activities, such as re-gravelling and surfacing of unsealed roads, need a more sophisticated process that includes predictive models. A major consideration during these analyses involves the economic appraisal of different maintenance options and timings of intervention.

Visual inspection can be a useful tool to provide snapshot of unseal road network at a time. Most road agencies still use this visual inspection as a maintenance strategy tool. It is recommended in this study to integrate visual inspection with localised gravel loss model and roughness data. GPS based data can be integrated by using visual inspections, roughness and the gravel model.

\section{REFERENCES}

Australian RuralRoads Group, 2010, Going Nowhere: The rural local road crisis Its national significance and Proposed Reforms, Australian Rural Roads Group, NSW, Australia.

Scenic Rim Regional Council (SRRC)(2018), 2018-19 Community Budget Report Scenic Rim Regional Council, Scenic Rim Regional Council, Beaudesert, Australia

Alzubaidi, H. and Magnusson, R., 2002. Deterioration and Rating of Gravel Roads: State of the Art. Road Materials and Pavement Design, 3(3), pp.235-260.

McManus, K.J., 1994. Pavement deterioration models for a local government authority. In 17th ARRB conference, gold coast, Queensland, 15-19 August 1994; Proceedings; volume 17, part 4.

Lea, J.D., Paige-Green, P. and Jones, D., 1999. Neural networks for performance prediction on unsealed roads. Road \& Transport Research, 8(1), p.57.

Henning, T.F., McCaw, A., Bennet, N., 2019. Assessment Process for the Condition of Unsealed Roads, NZ Transport Agency research report 652

Henning, T.F., Flockhart, G., Costello, S.B., Jones, V. and Rodenburg, B., 2015. Managing gravelroads on the basis of fundamental material properties (No. 15-2562).

Henning, T., Giummarra, G.J. and Roux, D.C., 2008. The development of gravel deterioration models for adoption in a New Zealand gravel road management system (No. 332).

Martin, T. and Choummanivong, L., 2016. The benefits of Long-Term Pavement Performance (LTPP) research to funders. Transportation Research Procedia, 14, pp.2477-2486.

Giummarra, G., 2009. Unsealed Roads Manual: Guidelines to Good Practice, 2009 ed. Australian 
Road Research Board, Melbourne, Victoria, Australia.

Road Infrastructure Management Support (RIMS), 2015, Unsealed Roads Tactical Asset Management Guide, RIMS, New Zealand.

Jones, D., Paige-Green, P. and Sadzik, E., 2003. Development of guidelines for unsealed road assessment. Transportation Research Record: Journal of the Transportation Research Board, (1819), pp.287-296.

\section{ACKNOWLEDGMENTS}

Authors would like to acknowledge Chris Gray, General Manager, Infrastructure Services from Scenic Rim Regional Council for providing his support for this research project.

\section{TABLES}

Table 1. Inspection frequency based on Road category

\begin{tabular}{|c|c|c|c|c|c|c|c|}
\hline $\begin{array}{l}\text { Road } \\
\text { Category }\end{array}$ & $\begin{array}{l}\text { 4a: Rural } \\
\text { Connector }\end{array}$ & $\begin{array}{l}\text { 4b: Rural } \\
\text { Collector }\end{array}$ & $\begin{array}{l}\text { 5a: Rural } \\
\text { Access }\end{array}$ & $\begin{array}{l}\text { 5b: Rural } \\
\text { Access }\end{array}$ & $\begin{array}{l}\text { 5c: Rural } \\
\text { Access }\end{array}$ & $\begin{array}{l}5 \mathrm{~d} \text { : Rural } \\
\text { Access }\end{array}$ & $\begin{array}{l}\text { 5b: Rural } \\
\text { Access }\end{array}$ \\
\hline $\begin{array}{l}\text { Traffic } \\
\text { Volume } \\
\text { (ADT) }\end{array}$ & $1000-3000$ & $500-1000$ & $150-500$ & $80-150$ & $40-80$ & $10-40$ & $2-10$ \\
\hline $\begin{array}{l}\text { Inspection } \\
\text { Frequency }\end{array}$ & Monthly & Monthly & $\begin{array}{l}3 \\
\text { Monthly }\end{array}$ & $\begin{array}{l}4 \\
\text { Monthly }\end{array}$ & $\begin{array}{l}4 \\
\text { Monthly }\end{array}$ & $\begin{array}{l}4 \\
\text { Monthly }\end{array}$ & $\begin{array}{l}6 \\
\text { Monthly }\end{array}$ \\
\hline
\end{tabular}

Table 2. Visual condition rating criteria

\begin{tabular}{|c|c|c|c|c|c|}
\hline Score & $\begin{array}{l}\text { Loss } \\
\text { Material }\end{array}$ & Roughness & $\begin{array}{l}\text { Scouring \& } \\
\text { Potholes }\end{array}$ & Corrugations & Shape \\
\hline 1 & $\mathrm{Nil}$ & Very Good & $\mathrm{Nil}$ & Nil & Clear Crown \\
\hline 2 & $\begin{array}{l}\text { Sporadic \& } \\
\text { Minor }\end{array}$ & Good & $<10 \%$ \& Minor & Just Perceptible & No Crown \\
\hline 3 & $\begin{array}{l}\text { Significant } \\
\& \\
\text { Substantial }\end{array}$ & Fair & $\begin{array}{l}<25 \% \& \\
\text { Moderate }\end{array}$ & Mild $<25 \mathrm{~mm}$ & Mild Rutting <25mm \\
\hline 4 & $\begin{array}{l}\text { Extensive } \\
\& \\
\text { Substantial }\end{array}$ & Poor & $<50 \%$ or Extreme & $\begin{array}{l}\text { Significant } \\
<50 \mathrm{~mm}\end{array}$ & Deep Rutting $<75 \mathrm{~mm}$ \\
\hline 5 & $\begin{array}{l}\text { Extensive } \\
\text { \& Extreme }\end{array}$ & Extreme & $>50 \%$ \& Extreme & Extreme $>50 \mathrm{~mm}$ & $\begin{array}{l}\text { Extreme Rutting } \\
>75 \mathrm{~mm}\end{array}$ \\
\hline 9 & $\begin{array}{l}\text { No Gravel } \\
\text { Present }\end{array}$ & Variable & $\mathrm{N} / \mathrm{A}$ & N/A & Track Only \\
\hline
\end{tabular}




\section{FIGURES}
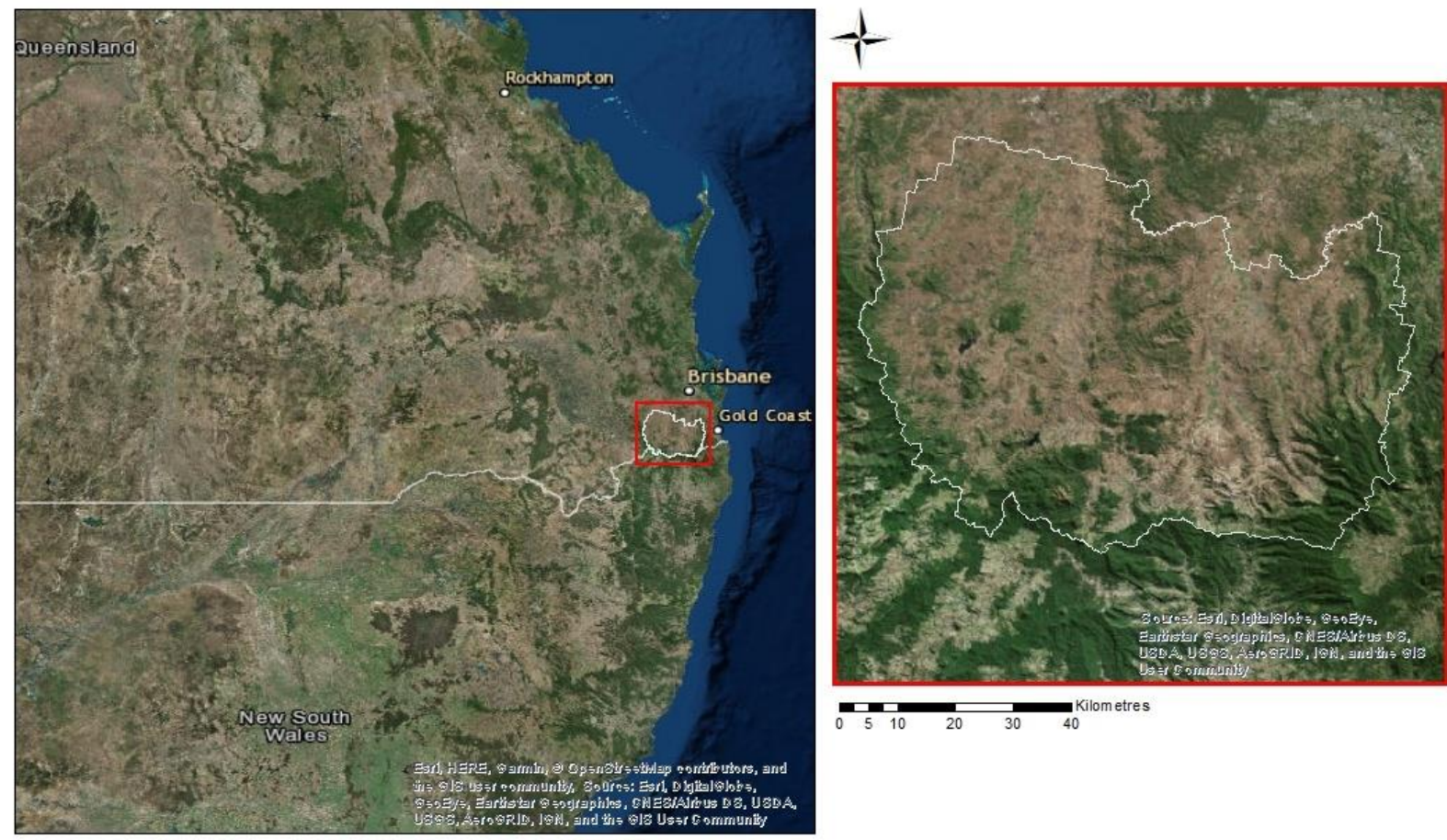

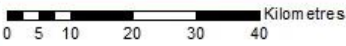

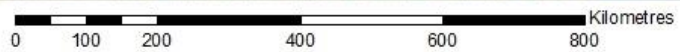

FIG. 1. Scenic Rim Regional Council map

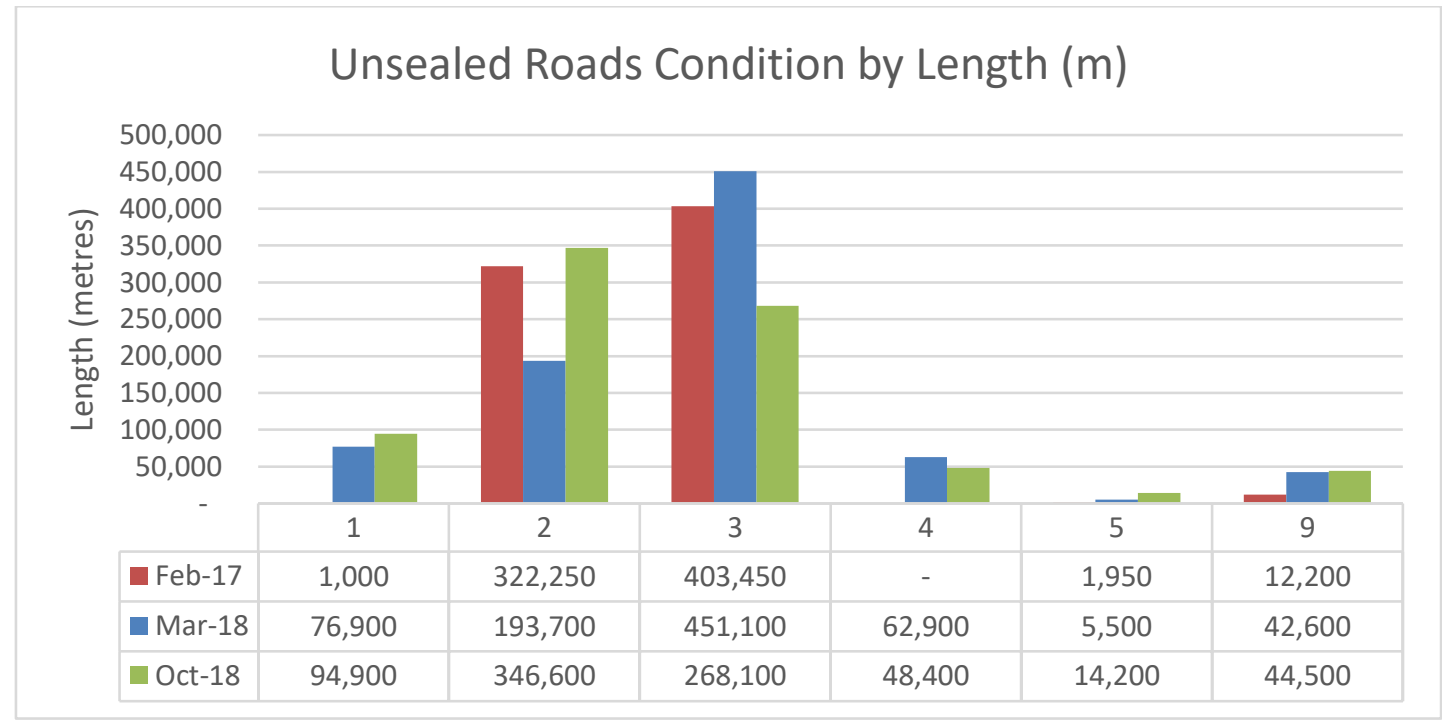

FIG. 2. Unsealed Road condition by length during 2017 -2018 


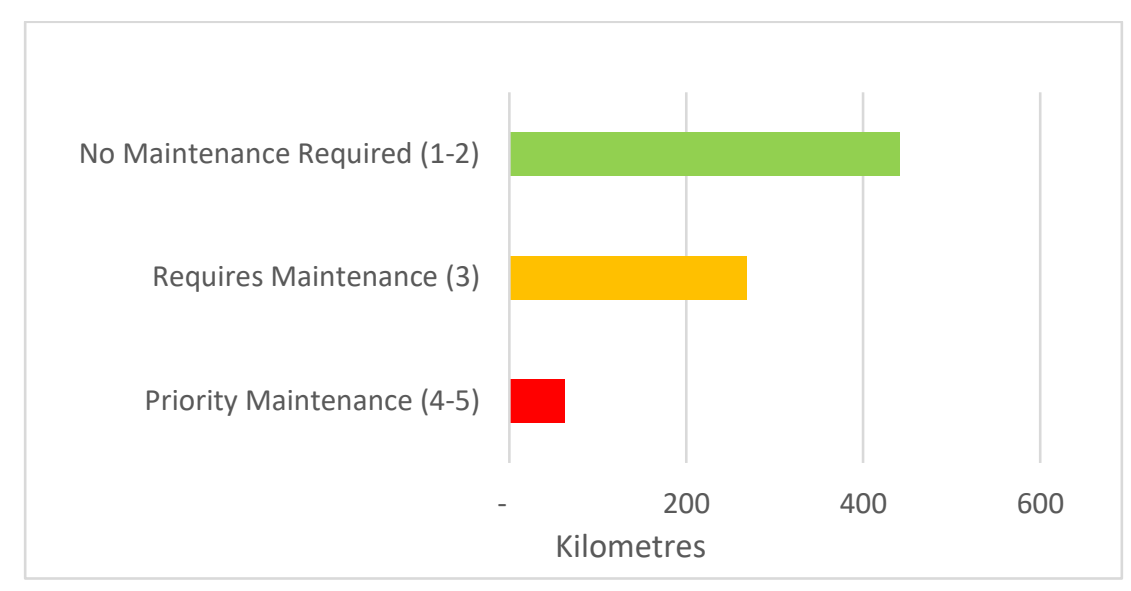

FIG. 3. Unsealed Road maintenance strategy

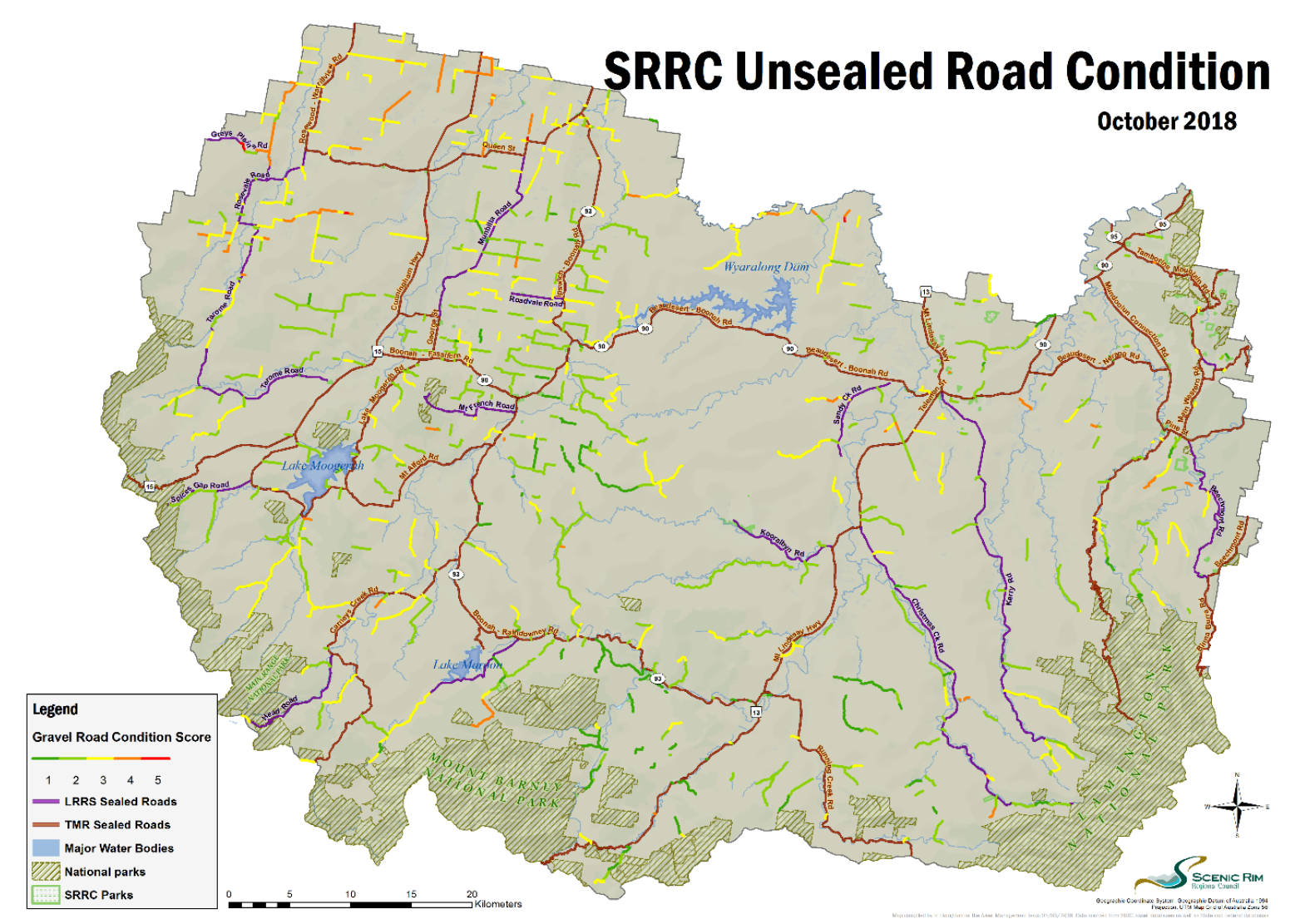

FIG. 4. SRRC Unsealed Road condition map. 